\title{
Opportunities for Standards to Contribute to Health, Safety, Resiliency, and Environmental Protection in Canada's North
}

\author{
Paul Steenhof \\ CSA Group
}

\begin{abstract}
The objective of this research and article is to investigate potential opportunities for standards to contribute to increased health, safety, resiliency, and environmental protection in Canada's North. Specifically, we focus attention on four key topic areas where there are unique considerations in Canada's North relative to the potential role for standards and also a number of identified challenges: the provision of clean and accessible water, the provision of adequate emergency response, having safe and resilient buildings to live and work in, and environmental protection and management. Fourteen different opportunities for standards have been identified across these topic areas. The article also highlights that there are needs and opportunities in terms of better allowing for the inclusion of northern perspectives and input into northern standards and presents three distinct ideas for helping to achieve this.
\end{abstract}

The Northern Review 48 (2018): 33-50

Published by Yukon College, Whitehorse, Canada 


\section{Introduction}

The objective of this research was to investigate potential opportunities for standards to contribute to increased health, safety, resiliency, and environmental protection in Canada's North. Specifically, we focused attention on four key topic areas where there are unique considerations in Canada's North relative to the potential role for standards and also a number of identified challenges: the provision of clean and accessible water, the provision of adequate emergency response, having safe and resilient buildings to live and work in, and environmental protection and management. This article draws upon a white paper published by CSA Group that undertook a broader review of the potential for standards to help address issues and challenges facing Canada's North (CSA Group 2017).

One of the key motivations underlying this research is that northern Canada's unique environment and geography often necessitates different processes, procedures, and technologies than those used in southern Canada, with a commensurate need for related standards to reflect these differences. For example, many buildings in Canada's North are located in regions underlain by permafrost, with this often requiring the use of specific technologies or specialized engineering procedures to mitigate permafrost degradation. Compared to more southern and warmer locales, the cold ambient temperatures in the North often mean the use of different types of, or performance requirements for, personal protective equipment across a range of applications. The cold also results in different rates of environmental processes such as decomposition. Additionally, Canada's North has been experiencing significant environmental and economic changes in recent years, particularly those related to climate change, which is amplified in the Arctic. These factors may even further necessitate the need for standards specifically geared towards northern issues and realities.

\section{Methodology}

A literature review was conducted in order to help identify and better understand the key topic areas highlighted. A consultation approach was then used to help further understand these topics as well as to understand if there could be opportunities and a role for standards in helping to 
improve human health, safety, resiliency, and environmental protection. Over the course of this study, CSA Group had ongoing contact with a cross section of professionals and organizations active and involved in and with the North.

The next step involved assessing ideas of where standards could help contribute to health, safety, resiliency, and environmental protection in Canada's North. Three key criteria were used to help prioritize thesesocietal benefit, urgency, and feasibility (see Figure 1). In applying these criteria, the ideas for standards were ranked highest where it was identified there would be a societal benefit, where the idea was feasible to achieve, and where there was urgency to do so (i.e., where all three circles intersect in Figure 1).

With respect to possible societal benefits, attention was focused on the protection of human health, promotion of safety, and the protection of the environment. Urgency was considered with respect to the immediacy of expected benefits in dealing with the challenge. Feasibility was considered largely in terms of whether the topic area is ready for standards to be developed and applied.

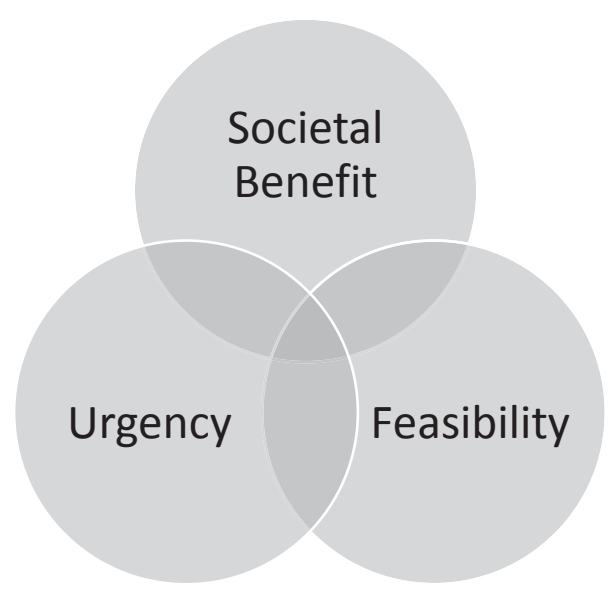

Figure I. Criteria used to help prioritize ideas for standards in Canada's North 


\section{The Case and Role for Standards}

\subsection{Importance, Definition, and Enforcement}

Standards are important tools for business, regulators, and for society generally as standards specify rules to help ensure uniform application of a policy or procedure, while also helping to mainstream the use and application of best practices. The typical purpose of a standard is to specify expectations and provide a means to measure compliance with its provisions. They usually contain a mix of requirements and recommendations, and are written in a way that the user can demonstrate compliance with the content. In this way, standards are often referenced in regulations so that they can be used for regulatory purposes and enforced as such. Standards are therefore often key instruments used to help achieve broad societal objectives related to safety, performance, environmental protection, and so on.

Fully accredited (and enforceable) standards are developed in such a way that their final content is determined by consensus, through the efforts of a balanced committee of stakeholders where no one interest group dominates. Standards development organizations (like CSA Group) help ensure that this consensus-based drafting process is adhered to. These organizations are audited by the Standards Council of Canada for compliance with best standards practices.

\subsection{Key Examples of Standards Driving Societal Outcomes and Benefits}

Standards are instruments with a long history of use-by some accounts dating back to the beginning of recorded history (American National Standards Institute 2016) —with often far-reaching societal benefits. There are a number of examples that help illustrate the possible benefits of standards and their use in society.

One relatively early example that had far-reaching impacts and benefits, particularly in terms of allowing for consistency and efficiencies in industrial production, was that of the standardization of screw thread sizes (American Society of Mechanical Engineers.). Throughout the nineteenth century, this relatively straightforward process of standardization helped transform a number of key industries, including marine engineering and ship building, and it then spread throughout the general manufacturing sector. 
More recently, a series of standards that have had significant uptake and use by policy-makers are the ISO 14000 environmental management standards. According to a recent review by the International Organization for Standardization, ${ }^{1}$ many countries-for example, many European countries, the United Kingdom, Japan, Australia, a number of Asian countries, as well as Canada-all directly reference these standards or use them voluntarily to meet public policy objectives. These include for purposes and outcomes such as managing the recycling of electronics (Sweden), enforcing sustainable development policy (France), or ensuring that environment management best practices are used for public works (Japan).

Another example more specific to Canada was the development of five CSA standards in response to significant safety and operational deficiencies that had contributed to the 1982 Ocean Ranger disaster (an offshore drilling rig that sank off the coast of Newfoundland and Labrador). By the late 1980s and early 1990s the first editions of these standards were published and subsequently referenced in the installation regulations for oil and gas related structures offshore Newfoundland and Nova Scotia. In the early 2000s the CSA standards were eliminated in order to adopt and adapt international standards covering the same topics. This allowed for the use of more up-to-date and internationally accepted design practices and knowledge, in turn facilitating the mobility of the workforce, eliminating trade barriers, and lowering costs due to the interchangeability of parts, shorter approval times, and so on.

\subsection{Potential for Canada's North}

Given the broader application of standards, what opportunities might exist for standards to help improve health, safety, and resiliency in Canada's North? Although standards might not be the only solution, standards are important tools that could be used in conjunction with other instruments and regulations, and with policies and programs to effect positive change. 


\section{Key Topics Investigated}

\subsection{The Provision of Clean and Accessible Water}

A topic area of great importance for any community is to have a safe and sufficient supply of water. However, there are a number of specific issues that face many northern communities in Canada. Some of the greatest challenges relate to climate change effects, infrastructure deficiencies, inconsistent testing and monitoring of source water, and difficulties in retaining trained and certified water treatment plant operators (Ripley 2009; Nesbitt 2010).

Climate change is resulting in increased precipitation, warmer temperatures, and permafrost degradation, with some of the most serious impacts being the increased risk for contamination from wastewater treatment effluents and leaching from solid waste sites. Furthermore, permafrost degradation can lead to structural failures in water and wastewater infrastructure components as well as in solid waste disposal sites.

Compounding the challenges posed by climate change, infrastructure issues-due to inappropriate design, construction, and maintenance processes-also impact water and wastewater treatment and distribution (Hazenberg, pers. comm.). In order to treat source water, many small northern communities use small-scale water treatment units (Ripley 2009). Ideally these should be operated by trained and certified operators; however, many communities experience great difficulties in finding and retaining these operators. The testing and monitoring of source water quality also plays a critical role in the effective treatment of drinking water. Testing has been found to be inconsistent in northern communities, resulting in an increased risk of incomplete treatment of source water, and, therefore, unsafe drinking water (Ripley 2009; Nesbitt 2010).

Another key challenge surrounding water treatment is preventing the overflow and leaching of wastewater from treatment lagoons into the environment (often a result of early and unplanned release). Many remote communities use "passive" wastewater treatment systems, such as lagoons, or a lagoon/wetland system, whereby water is stored and treated before being released into the environment (Ripley 2009). Nonetheless, although experts agree that such systems are the best wastewater treatment option, there is little guidance available for the design, construction, and operation of such systems. 
Solid waste facilities also represent a major concern. Most of these facilities in northern communities were built without an engineered liner in place, relying instead on permafrost as a natural barrier to prevent leaching of contaminants into groundwater and other freshwater sources (Ripley 2009; Nesbitt 2010; Canadian Council of Ministers of the Environment 2014). Such sites are highly susceptible to permafrost degradation. In many of the facilities that do have liners, the liners may be inappropriate for the facility or may not have been designed and installed according to cold climate conditions. Additional concerns surrounding waste disposal sites include the inappropriate disposal of hazardous waste, the overfilling of waste sites, and the challenges posed by composting in extreme low temperatures such as found in the Arctic environment.

\subsection{Adequate Emergency Response}

The remoteness of northern Canada, as well as the extreme climate, results in unique requirements related to emergency response, including ensuring that the performance of processes, equipment, and technologies meet these difficult conditions. These needs are heightened given expectations of increased vessel movement through Arctic waters due to climate change.

The mandate for establishing regulations for Canadian Arctic maritime emergency response falls under Transport Canada, which has adopted the International Maritime Organization's (IMO) Polar Code for ship operations in Arctic environments. Canada is involved in other relevant international efforts through the International Organization for Standards (ISO) as well as the Arctic Council. The entities in Canada that could be involved in an emergency and response situation in the North include:

- Canadian Air Force (CAF);

- Canadian Coast Guard (CCG);

- Canadian Coast Guard Auxiliary Vessels; and

- National Search and Rescue Secretariat (NSS), through Public Safety Canada.

The CAF, for example, has the capability to provide aeronautical and maritime search and rescue (SAR) services into the farthest and most remote locations in the Arctic region. The CCG is capable of providing SAR services on a seasonal basis through the deployment of icebreakers 
and some science vessels (National Defence and the Canadian Armed Forces 2016). Nonetheless, although Transport Canada does set forth rules and regulations for shipping, no separate set of regulations exist for SAR to respond to an Arctic event.

Another consideration associated with any increase in marine activity is the increased risk of oil and chemical spills (Government of Northwest Territories 2015). While there has been much research and development geared toward technologies for oil and chemical spill response in Arctic marine conditions (International Organization for Oil and Gas Producers 2016), much of this research has not yet been encompassed in standards that are widely available to industry and other stakeholders.

Other issues that contribute to the risk profile of the Arctic marine environment are related to the quality of navigation aids, inadequate hydrographic charts, and the availability of emergency and support services (e.g., ice breakers) (Council of Canadian Academies 2016; Office of the Auditor General of Canada 2014).

\subsection{Safe and Resilient Buildings}

Fundamental to human existence is a safe, resilient, and culturally appropriate living environment. However, a number of distinct issues related to northern buildings and their construction, an obvious key component of the living environment, have been identified.

Cold-climate conditions make building construction in the North a challenge. Permafrost conditions necessitate unique construction requirements and permafrost degradation further complicates construction (National Round Table on the Environment and Economy 2009). Climate change impacts construction methods and requires consideration of changing snow loads, wind, rain, and other northern conditions (Auld et al. 2010).

As buildings become more complex, achieving the proper operation of mechanical systems (e.g., heating systems); quality indoor environments (e.g., air quality, humidity levels); and proper building maintenance become more difficult. This is especially true given the environmental conditions, such as building on permafrost, as well as given the limited materials readily available in the North. Sourcing building systems and materials, as well as replacement parts, is challenging due to the relative lack of local materials and the long distances and costs involved in transporting these materials. 
Designing culturally-appropriate architecture is also a challenge (Canada Mortgage and Housing Corporation 2016). Neighbourhoods

are, in many cases, designed around southern Canadian interpretations of community, and houses are designed around southern Canadian concepts of how different rooms are used.

The technical challenges highlighted above are partially responsible for chronic and well-documented housing shortages (Canadian Polar Commission 2014). The need for northern housing policies and programs is being explored by various organizations (Pullat 2012; Skura 2016).

The National Building Code of Canada (National Research Council 2015), which is adopted by governments throughout the North, references some standards, including those published by CSA Group, that contain regional variations and address northern climatic conditions (e.g., fenestration energy performance). However, system flexibility and adaptation will remain challenges that need to be addressed given the rate of climate change.

\subsection{Environmental Protection and Management}

Protecting the northern environment as well as adapting to climate change presents a number of unique challenges. Paramount amongst these is that the northern environment is one of extreme conditions and highly sensitive to human impacts, and often with limitations in the availability of weather and environmental data.

One overarching challenge is how future climate change is accounted for with respect to climate-sensitive topics-i.e., from the planning, design, and construction of infrastructure, to issues relating to food security. In particular, feedback from many experts and practitioners has identified that there is a need for agreement on the best processes and procedures to factor future climate change into related decision-making, as well as the use of climate modelling and other tools used to project or account for environmental and climatic change.

A complicating challenge is that there are fewer stations that collect weather and environmental data in the North than in southern Canada. A lack of data could pose a challenge for numerous areas of public policy, regulations, and related decision-making. For example, this data might be necessary to help set requirements for buildings with respect to snow load, for the design of drainage systems, accounting for the effects of changes 
in permafrost for various infrastructure types, and many other issues (National Round Table on the Environment and Economy 2009).

In the mining sector, there are opportunities to advance procedures for adapting the design of tailings containment facilities to climate change and other unique environmental conditions (Pearce et al. 2010). Shoreline erosion due to reduced ice coverage causing more waves, in conjunction with increases in extreme weather, is also a concern that needs to be managed.

There are other key challenges related to environmental protection as well as environmental management. Waste management is an ongoing concern in northern communities (CBC 2015). The geographical range of plant and animal species are also changing, in turn impacting on both local ecosystems and the populations that depend on hunting and fishing for food and their livelihood.

\section{Assessing the Potential Impact of Standards across Key Topics}

Given the broader application of standards, what opportunities might exist for standards to help address key societal issues and challenges facing Canada's North? As noted earlier in the paper, although standards might not address all the challenges identified or be the only solution, standards are important tools that could be used in conjunction with other instruments and regulations, and policy and programs to effect positive change.

Through the consultation process outlined in Section 2.2, fourteen specific ideas on standards-based contributions were identified as summarized in Table 1.

The topics considered were then assessed according to the three criteria defined in Section 2-namely, the societal benefit resulting from addressing these, their urgency, and the feasibility for standards. Three possible rankings were considered: high, medium, or low. The results are summarized in Table 2.

All four topics have potential implications for human health and safety, and all were deemed to have significant societal benefits as well as being urgent to address given the close relationship between these topics and the well-being of those living in, working in, or visiting the

North. This interpretation also corresponds with the basic premise that 
the physiological needs of water, warmth, and rest; the need for safety and security; and having a clean environment are the building blocks of a healthy society.

Table I. Possible standards-based contributions to the Canadian North

\begin{tabular}{|c|c|}
\hline Thematic Area & Purpose and Intended Outcome \\
\hline \multirow{3}{*}{ Water } & $\begin{array}{l}\text { The assessment of water treatment facilities and the design/ } \\
\text { improvements of such facilities }\end{array}$ \\
\hline & $\begin{array}{l}\text { The design, construction, operation, and maintenance of } \\
\text { wastewater treatment lagoons, wetlands, and lagoon/wetland hybrid } \\
\text { systems }\end{array}$ \\
\hline & $\begin{array}{l}\text { The design, construction, operation, and maintenance of solid waste } \\
\text { disposal sites, including the use of engineered liners }\end{array}$ \\
\hline \multirow{3}{*}{$\begin{array}{l}\text { Emergency } \\
\text { response }\end{array}$} & $\begin{array}{l}\text { The capacity of first responders and the availability and use of } \\
\text { technologies and equipment for emergency response (including } \\
\text { requirements for on-board vessels) }\end{array}$ \\
\hline & $\begin{array}{l}\text { The performance of the personal protection equipment (PPE) used } \\
\text { in cold-climate conditions }\end{array}$ \\
\hline & $\begin{array}{l}\text { The detection, response, mitigation, and monitoring of Arctic oil/ } \\
\text { chemical spills, including the use of technologies, equipment, and } \\
\text { materials. }\end{array}$ \\
\hline \multirow{4}{*}{ Buildings } & $\begin{array}{l}\text { The enhancement of building foundations for cold-climate } \\
\text { conditions (i.e., beyond the requirements of the National Building } \\
\text { Code of Canada) }\end{array}$ \\
\hline & $\begin{array}{l}\text { The update/expansion of existing northern-based building } \\
\text { standards for other applications and users (e.g., CSA S500, } \\
\text { Thermosyphon foundations for buildings) }\end{array}$ \\
\hline & $\begin{array}{l}\text { The design and construction of modular structures for housing and } \\
\text { municipal buildings to better reflect the culture of Canada's North }\end{array}$ \\
\hline & $\begin{array}{l}\text { The adoption of standards referenced in the National Building Code } \\
\text { of Canada and data used within to incorporate changing climate } \\
\text { conditions }\end{array}$ \\
\hline \multirow{4}{*}{$\begin{array}{l}\text { Environmental } \\
\text { protection }\end{array}$} & The disposal of municipal solid waste in northern communities \\
\hline & $\begin{array}{l}\text { The adoption of existing standards or the development of new } \\
\text { ones for the design of northern tailings containment facilities }\end{array}$ \\
\hline & $\begin{array}{l}\text { Best practices with respect to factoring future climate change into } \\
\text { relevant decision-making, as well as the use of climate modelling }\end{array}$ \\
\hline & The minimization/mitigation of the effects of shoreline erosion \\
\hline
\end{tabular}


Table 2. Ranking of ideas for standards in the Canadian North

\begin{tabular}{lccc}
\hline Topic & Societal benefit & Urgency & Feasibility \\
\hline Water & High & High & High \\
Emergency response & High & High & High \\
Buildings & High & High & High \\
$\begin{array}{l}\text { Environmental } \\
\text { protection }\end{array}$ & High & High & Medium \\
\hline
\end{tabular}

For water, emergency response, and buildings, it is noted that for many issues and topics there is already an existing knowledge base as well as readily available stakeholders to contribute to the standards development process. For example, there are already existing standards such as CAN/ CSA-S500-14-Thermosyphon foundations for buildings in permafrost regions and also the National Model Building code, which provide a strong basis to build from in terms of content and the technical expertise and experience reflected. Meanwhile, existing documents related to emergency response may offer important starting points that can be adapted for use and application for northern characteristics and regions.

It is also noted that CSA Group is actively managing the development of standards or further investigating topics highlighted in this article. Specifically, a new standard covering wastewater treatment in northern communities using lagoon and wetland systems is currently being developed, with publication planned for 2019. A balanced group of stakeholders representing owner/operators, regulatory/policy/underwriter interests, consultants, and others such as those in the research community are engaged on this project. CSA Group is also working with Yukon College to further investigate needs with respect to standards and related documents (e.g., standards; guidance documents; as well as related training, certification, testing, and so on) covering the topic of small-scale water distribution and wastewater systems in Canada's North.

\section{The Need to Include Northerners and Northern Perspectives}

Crossing nearly all the topics investigated, one central theme that emerges is the need for the involvement of northerners, and particularly the Indigenous populations, in helping to address these. The inclusion of northern perspectives is an opportunity that is receiving increasing attention more broadly, with recognition that this can help ensure the applicability, 
acceptance, and ultimate success of northern-focused initiatives (Pearce et al. 2009; Gearheard and Shirley 2007).

One key reason underpinning the need to include northerners' input, including Indigenous and local knowledge, is that these stakeholders often retain pivotal knowledge on the geophysical, cultural, and socioeconomic realities of Canada's North gained through direct observation as well as passed along intergenerationally (Weatherhead, Gearheard, and Barry 2010; Thornton, Scheer, and Maciejewski 2012; Johnson et al. 2015; Laidler 2006).

Nonetheless, there are a number of related challenges and barriers that have proven difficult in allowing for the inclusion of both northern perspectives and data in northern-based policy and decision-making (Ellis 2005). In particular, those involved specifically with the development of standards have expressed that they face uncertainty and limitations in how to best engage northerners on these initiatives. A number of interacting and often mutually reinforcing factors have been cited, including those outlined in Figure 2.
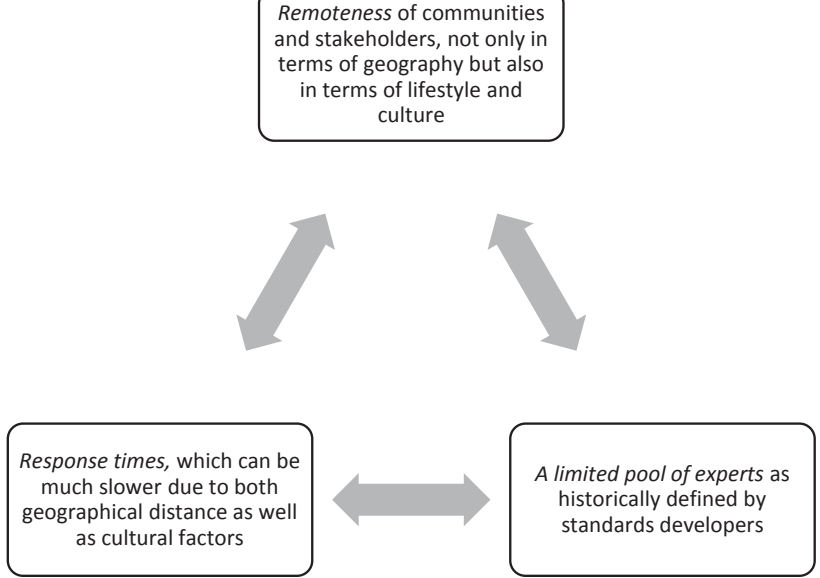

Figure 2. Factors limiting northern participation in standards development 
Both cultural and technical factors contribute to and exacerbate the above factors. Culturally, the lifestyles of many northerners, particularly those outside of the main population centres, is strongly impacted by the need to hunt and fish. At the same time, not only might there be poor internet connectivity, there may also be limitations in the use of computers or cell phones that can be used for communications.

These factors also might impact other practitioners within other sectors, including those in research, policy-making, or other areas. Furthermore, the definition of "expert" may also need to be expanded, not only for standards development but, more broadly, to include holders of traditional knowledge and Indigenous perspectives since, historically, "experts" have been viewed largely as those gaining knowledge through academic study, research, business activities, or a combination thereof.

As a result of this assessment and consultation exercise, three additional opportunities have been identified specific to the engagement and inclusion of northerners and northern perspectives in standards:

- The mainstreaming of best practices for the engagement of Indigenous and non-Indigenous northerners in standards development initiatives;

- The engagement of communities and other stakeholders on the application/use of standards; and

- The inclusion of Indigenous people and traditional knowledge in the development of northern data and information, including the use of community-based monitoring.

\section{Summary}

Standards have a crucial role to play as part of the larger toolbox for helping to address human health, safety, resiliency, and environmental protection in Canada's North. Through consultation with a wide range of stakeholders and a literature review, fourteen different opportunities for standards development have been identified specific to the topic areas of water, emergency response, buildings, and environmental protection and management. Of these, the greatest priorities have immediate ties to human health, safety, and resiliency. 
Northerners need to be part of any process for addressing these issues and the process of standards development offers a valuable opportunity to help make this happen in a collaborative and consensus-based way. Three specific ideas for the better inclusion of northerner and northern perspectives have also been presented. However, effectively addressing and advancing issues specific to health, safety, resiliency, and environmental protection in Canada's North will require building upon successes and lessons learned, as well as engaging both the affected stakeholders and the relevant knowledge base for given challenges or opportunities. Partnering and collaborating with other stakeholders will also be crucial as the issues are complex and interlinked. This will all be essential to support and foster the development of solutions that lead to the sustainability of Canada's North.

\section{Acknowledgements}

CSA Group would like to thank the interviewees who gave of their time and expertise so generously. The work was overseen and guided by a CSA leadership team made up of Helene Vaillancourt, Michael Leering, and Doug Morton.

\section{Authors}

Paul Steenhof, $\mathrm{PhD}$, is a project manager at CSA Group, Ottawa, Ontario.paul.steenhof@csagroup.org

\section{Notes}

1. See https://www.iso.org/sites/policy/sectorial examples.html.

\section{References}

American National Standards Institute. 2016. Through History with Standards. Accessed December 2016. https://www.ansi.org/consumer affairs/history standards.aspx.

American Society of Mechanical Engineers. 2017. "The United States Standard Screw Threads." Accessed January 2, 2017. https:// www.asme.org/about-asme/who-we-are/engineering-history/ landmarks/234-the-united-states-standard-screw-threads. 
Auld, H., J. Waller, S. Eng, J. Klaassen, R. Morris, S. Fernandez, V. Cheng, and D. MacIver. 2010. "The Changing Climate and National Building Codes and Standards." Proceedings of the American Meterological Society, Ninth Symposium on the Urban Environment, Session 5.6, August 2010. Keystone, Colorado.

Canadian Council of Ministers of the Environment. 2014. Canada-Wide Strategy for the Management of Municipal Wastewater Effuent 2014 Progress Report. Accessed December 2016. http://www.ccme.ca/files/Resources/municipal wastewater efflent/PN 1522 MWWE Five Year Rvw 2014.pdf.

Canada Mortgage and Housing Corporation. 2016. "Designing Sustainable Northern Houses and Communities.” Accessed December 2016. https:// www.cmhc-schl.gc.ca/en/inpr/bude/noho/noho 002.cfm.

Canadian Polar Commission. 2014. Housing in the Canadian North: Recent Advances and Remaining Knowledge Gaps and Research Opportunities. Accessed December 2016.http://www.polarcom.gc.ca/sites/default/files/housing_summary_1. pdf.

CBC. 2015. "Waste Management a Big Issue Facing Yukon Communities." Accessed January 2, 2017. http://www.cbc.ca/news/canada/north/ waste-management-a-big-issue-facing-yukon-communities-1.3068763.

Council of Canadian Academies. 2016. Commercial Marine Shipping Accidents: Understanding the Risks in Canada Ottawa: Council of Canadian Academies, 84.

CSA Group. 2017. Canada's North: Discovering How Standards Can Contribute to Safety, Sustainability \& Economic Growth. Toronto: CSA Group.

Ellis, S. 2005. "Meaningful Consideration? A Review of Traditional Knowledge in Environmental Decision Making.” Arctic 58 (1): 66-77.

Gearheard, S., and J. Shirley. 2007. "Challenges in Community-Research Relationships: Learning from Natural Science in Nunavut.” Arctic 60 (1): 62-74.

Government of Northwest Territories. 2015. Trends in Shipping in the Northwest Passage and the Beaufort Sea, State of the Environment Report. Accessed January 2017, http://www.enr.gov.nt.ca/ state-environment/73-trends-shipping-northwest-passage-and-beaufort-sea.

International Organization for Oil and Gas Producers. 2016. "Arctic Response Technology -Oil Spill Preparedness Joint Industry Programme.” Accessed December 2016. http://www.arcticresponsetechnology.org/contact. 
Johnson, N., L. Alessa, C. Behe, F. Danielsen, S. Gearheard, V. GofmanWallingford, E.M. Krümmel, A. Kliskey, A. Lynch, T. Mustonen, and P. Pulsifer. 2015. "The Contributions of Community-Based Monitoring and Traditional Knowledge to Arctic Observing Networks: Reflections on the State of the Field." Arctic 68, Suppl. 1 (2015): 28-40.

Laidle, G.J. 2006. "Inuit and Scientific Perspectives on the Relationship between Sea Ice and Climate Change: The Ideal Complement?” Climatic Change 78: 407.

National Defence and the Canadian Armed Forces. 2016. "Search and Rescue Canada.” Accessed December 2016. http://www.forces.gc.ca/en/operationscanada-north-america-current/sar-canada.page.

National Research Council. 2015. National Building Code of Canada (2015). Ottawa: National Research Council.

National Round Table on the Environment and Economy. 2009. True North: Adapting Infrastructure to Climate Change in Northern Canada. Ottawa: National Round Table on the Environment and Economy, 1-50.

Nesbitt, L. 2010. Assessment of the Vulnerability of Deline's Water and Wastewater Systems to Climate Change Impacts. Accessed December 2016. http:// ecologynorth.ca/wp-content/uploads/2015/07/Deline-VulnerabilityAssessment-03-10-Compressed.pdf.

Office of the Auditor General of Canada.2014.2014 Fall Report of the Commissioner of the Environment and Sustainable Development. Accessed December 2016. http://www.oag-bvg.gc.ca/internet/English/parl cesd 201410 e 39845. html.

Pearce, T.D., B. Smit,J.D. Ford, M. Beaumier, L. Berrang-Ford,J.Prno, F. Deurden, and J. Pittman. 2010. Climate Change and Mining in Canada. Mitigation and Adaptation Strategies for Global Change. https://www.researchgate.net/ profile/Lea Berrang-Ford/publication/229032096 Climate change and mining_in_Canada/links/00b7d538ca14e20131000000.pdf.

Pearce, T., J. Ford, G. Laidler, B. Smit, F. Duerden, M. Allarut, M. Andrachuk, S. Baryluk, A. Dialla, P. Elee, A. Goose, T. Ikummaq, E. Joamie, F. Kataoyak, E. Loring, S. Meakin, S. Nickels, K. Shappa, J. Shirley, and J. Wandel. 2009. "Community Collaboration and Climate Change Research in the Canadian Arctic." Polar Resarch 28 (1): 10-27.

Pullat, S. 2012. Framing Sustainable Options for Housing in Canada's North, Ottawa: The Conference Board of Canada. 
Ripley, S. 2009. Navigating the Waters of Change. Accessed December 2016. http:// ecologynorth.ca/wp-content/uploads/2015/07/Navigating-the-Waters-ofChange-FINAL-May-09.pdf.

Skura, E. 2016. "Senators Head North to Study Inuit Housing Crisis." CBC News, April 14, 2016. Accessed December 2016. http://www.cbc.ca/news/ canada/north/senate-canada-inuit-housing-crisis-1.3534512.

Thornton, T., A. Scheer, and A. Maciejewski. 2012. "Collaborative Engagement of Local and Traditional Knowledge and Science in Marine Environments: A Review." Ecology and Society17(3):8.https://doi.org/10.5751/ES-04714-170308.

Weatherhead, E., S. Gearheard, and R.G. Barry. 2010. "Changes in Weather Persistence: Insight from Inuit Knowledge.” Global Environmental Change 20(3): 523-528. 